\title{
Power Quality Improvement for Thirty Bus System using UPFC and TCSC
}

\author{
S. Marlin*, S. D. Sundarsingh Jebaseelan, B. Padmanabhan and G.Nagarajan \\ Sathyabama University, Chennai, India; sagayarajmarlin@gmail.com, sundarjeba@yahoo.co.in
}

\begin{abstract}
This work deals with power quality improvement by using FACTS devices. When the reactive power of the load is changing continuously, a suitable fast response compensator is needed. Unified Power Flow Controller and Thyristor Controller Series Capacitor are two such compensators belonging to FACTS devices which are used in this work. Models for the UPFC and TCSC are developed using MATLAB Simulink. The simulation results for thirty bus system with UPFC and TCSC are presented.
\end{abstract}

Keywords: FACTS Controller, MATLAB, Simulink, TCSC, UPFC

\section{Introduction}

FACTS technology consists of high power electronic based equipments with its real time operating control. There are two groups of FACTS controllers based on different technical approaches, both resulting in controllers able to solve transmission problems. The first group employs reactive impedances or tap-changing transformers with thyristor switches as controlled elements; the second group employs self-commutated voltage source switching converters. The Static Var Compensators (SVC), Thyristor Controlled Series Capacitor, (TCSC) and Phase Shifter, belong to the first group of controllers while Static Synchronous Compensator (STATCOM), Static Synchronous Series Compressor (SSSC), Unified Power Flow Controller (UPFC) and inter Interline Power Flow Controllers (IPFC) belong to the group ${ }^{1,2}$.

FACTS technologies allow for improved transmission system operation with minimal infrastructure investment, environmental impact, and transmission lines. Traditional solutions to upgrading the electrical transmission system infrastructure solution to upgrading the electrical transmission system infrastructure have been primarily in the form of new transmission lines, substations, and associated equipment However, as experiences have proven over the past decade or more, the process to permit, site and construct new transmission lines has become extremely difficult, expensive, time-consuming, and controversial. FACTS technologies provide advanced solutions as cost-effective alternatives to new transmission line construction ${ }^{3,5}$.

\subsection{Benefits of FACTS Devices}

- Better utilization of existing transmission system.

- Increase quality of supply.

- Increased transmission system by reliability and availability.

- Increased dynamic and transient grid stability and reduction of loop flows.

\section{Unified Power Flow Controller (UPFC)}

In the FACTS family, UPFC is one of the most powerful and versatile FACTS devices available so far. Being able to almost instantaneously insert a synchronous voltage of arbitrary magnitude (within a pre-specific range) and

*Author for correspondence 
phase angle (with respect to the sending-end voltage) into the transmission line, UPFC can be used to adjust the real electrical power output of an electric power system in real time. Thus, UPFC is regarded by many researches as an ideal candidate for improving the transient and dynamic performance of an electric power system. The UPFC is incorporated into the Phillips-Heffron model of a linearized power system. Dramatic improvement in dynamic stability performance is reported in their study $\mathrm{y}^{6,7}$.

Figure 1 shows the block diagram of UPFC. The UPFC is a FACTS controller developed so far, with all-encompassing capabilities of voltage regulation, series compensation, and phase shifting. It can independently and very rapidly control both real and reactive power flows in a transmission line. Its configured is shown in the above diagram and comprises two VSCs coupled through a common dc terminal. One VSC convertor is connected in shunt with the link through a coupling transformer, the other VSC convertor is inserted in series with the transmission line through an interface transformer. The DC voltage for both convertors is provided by a common capacitor bank ${ }^{8,9}$.

The UPFC operates with constraints on the following variables:

1. The series-injected voltage magnitude.

2. The line current through series convertor.

3. The shunt-convertor current.

4. The minimum line-side voltage of the UPFC.

5. The maximum line-side voltage of the UPFC and

6. The real-power transfer between the series convertor and the shunt convertor

\section{Thyristor Control Series Capacitor (TCSC)}

Figure 2 shows the block diagram for TCSC. The basic conceptual TCSC module comprises a series capacitor,

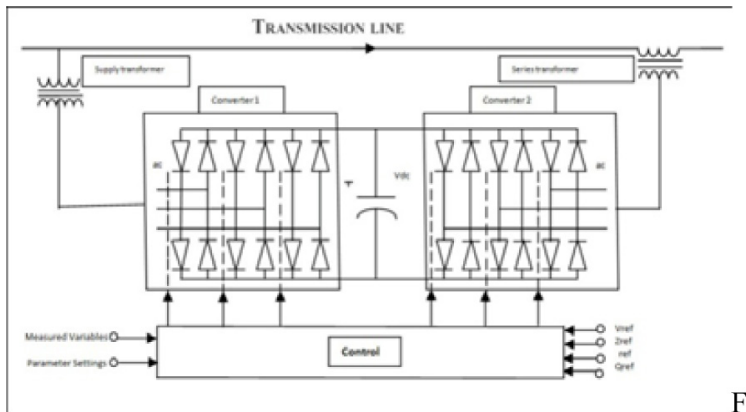

$\mathrm{Fi}$

Figure 1. Block diagram of UPFC.
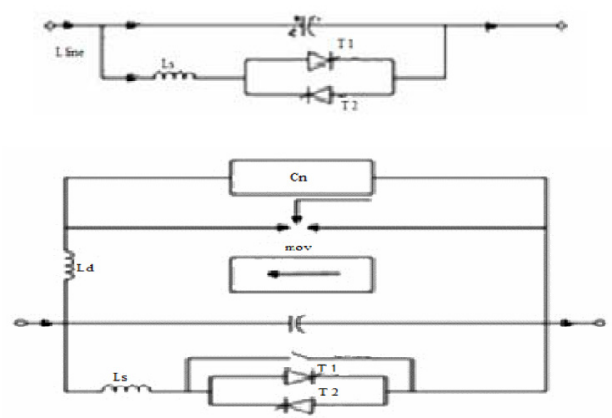

Figure 2. TCSC module

C, in a parallel with a thyristor - controlled reactor, Ls. However, a practical TCSC module also includes protective equipment normally installed with series capacitors.

A metal-oxide varistor (MOV), essentially a nonlinear resistor, is connected across the series capacitor to prevent the occurrence of high - capacitor over voltages. Not only does the MOV limit the voltage across the capacitor, but it allows the capacitor to remain in circuit even during fault conditions and helps improve the transient stability. Also installed across the capacitor is a circuit breaker, $\mathrm{CB}$, for controlling its insertion in the line. In addition, the $\mathrm{CB}$ bypasses the capacitor if serve fault or equipment malfunction events occur. A current - limiting inductor, $\mathrm{Ld}$, is incorporated in the circuit to restrict both the magnitude and the frequency of the capacitor current during the capacitor - bypass operation ${ }^{10,11}$.

If the TCSC valves are required to operate in the fully "on" mode for prolonged durations, the conduction losses are minimized by installing an ultra - high- speed contact (UHSC) across the valve. This metallic contact offers virtually lossless feature similar to that of circuit breakers and is capable of handling many switching operations. The metallic contact is closed shortly after the thyristor valve is turned on and it is opened shortly before the valve is turned off. During a sudden overload of the valve, and also during fault conditions the metallic contact is closed to alleviate the stress on the valve ${ }^{12}$.

\section{Simulaton Results}

\subsection{Thirty Bus System without Controller}

The simulation is done by using MATLAB simulink and the results are presented. Each line is moduled by its series impedance. The load at the load busses are represented by the combination of $\mathrm{R}$ and $\mathrm{L}$. The shunt capacitances of the 
line are neglected. The circuit model of thirty bus system without controller is shown in Figure 3. The voltage waveform at bus 21 without controller is shown in Figure 4. The real \& reactive power at bus 21 without controller is shown in Figure 5. The technical specification is as follows.

$\mathrm{V} 1=11 \mathrm{KV}, \mathrm{R}=30 \mathrm{Ohms}, \mathrm{L}=0.1 \mathrm{mh}$.

\subsection{Thirty Bus System with UPFC}

The simulation is done by using MATLAB Simulink and the results are presented. Each line is moduled by its series impedance. The load at the load busses are represented by

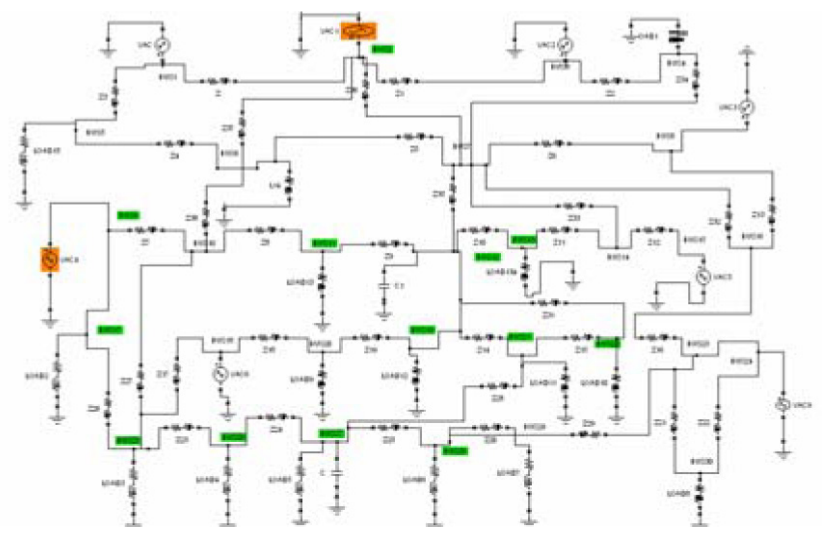

Figure 3. Thirty bus system without controller.

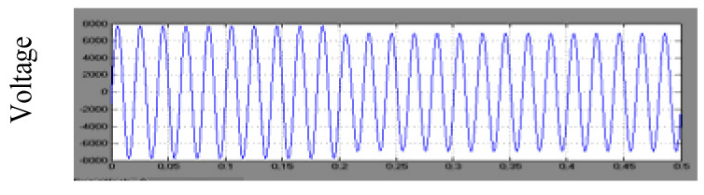

Time

Figure 4. Voltage waveform at bus 21 witout controller.

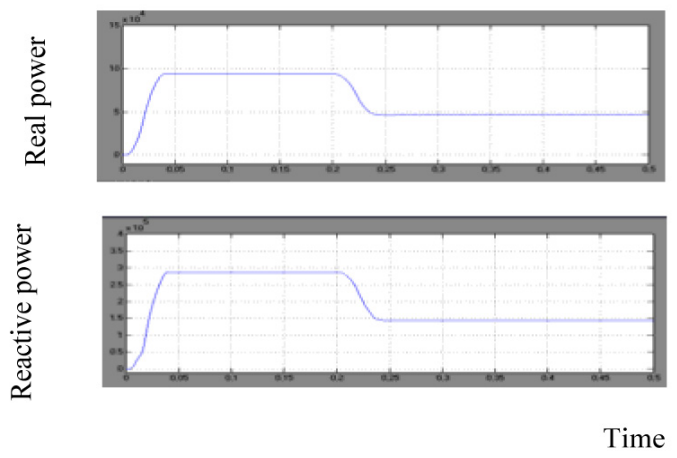

Figure 5. Real and Reactive waveform at bus 21 without controller. the combination of $\mathrm{R}$ and $\mathrm{L}$. The shunt capacitances of the line are neglected. The circuit model of thirty bus system with UPFC controller is shown in Figure 6. The voltage waveform at bus 21 with UPFC controller is shown in Figure 7. The real \& reactive power at bus 21 with UPFC controller is shown in Figure 8.

\subsection{Thirty Bus System with UPFC and TCSC}

Thirty bus system with UPFC and TCSC is simulated using MATLAB. Model of Thirty bus system with UPFC \& TCSC is shown in Figure 9. The voltage waveform

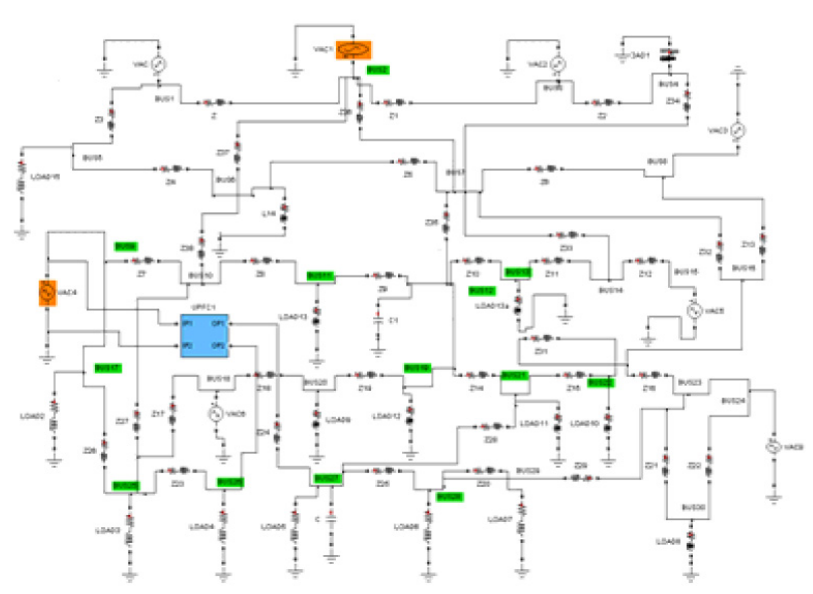

Figure 6. Thirty bus system UPFC.

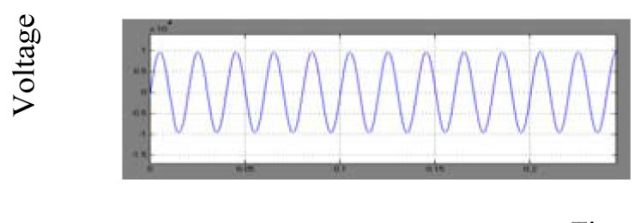

Figure 7. Voltage waveform at bus 21 with controller.

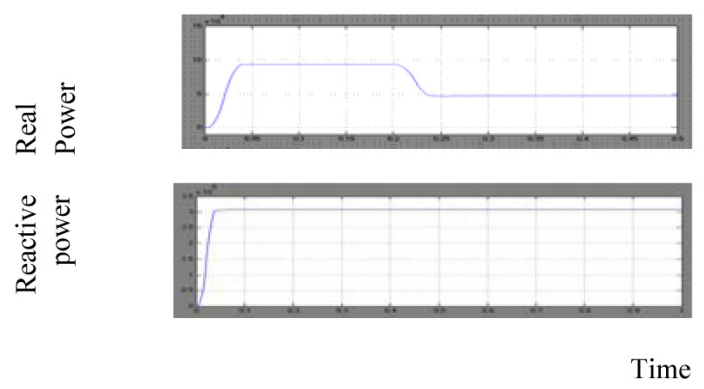

Figure 8. Real and Reactive power waveform at bus 21 . 


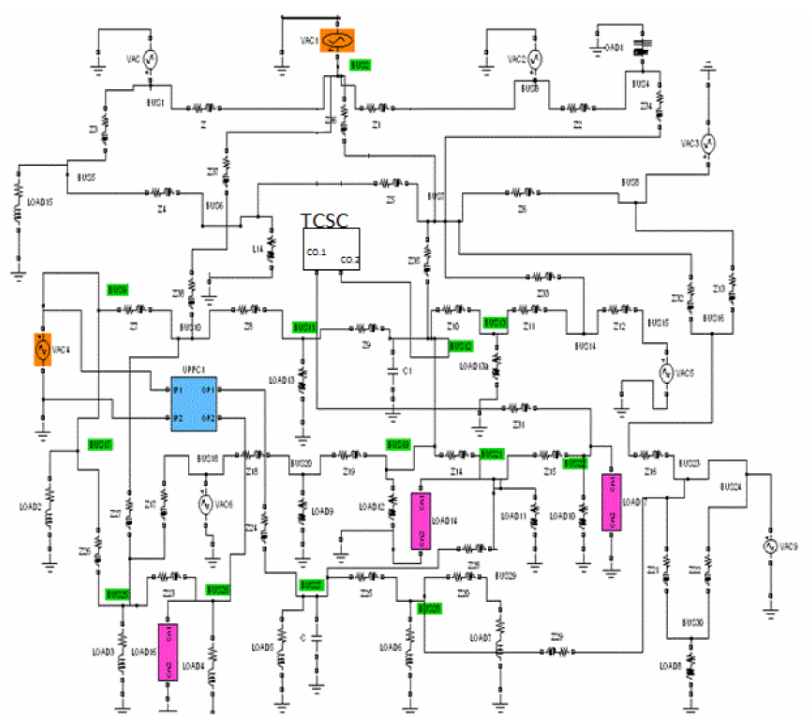

Figure 9. Thirty bus system with UPFC and TCSC.

at bus 21 with UPFC and TCSC controller is shown in Figure 10 . The real \& reactive power at bus 21 with UPFC and TCSC controller is shown in Figure 11. The increase of reactive power is due to increased difference between Sending \& Receiving end. The circuit model for TCSC is compensated by using UPFC.

The summary of real \& reactive power at various busses is given in Table 1.The summary of voltage with and without controller for thirty bus system is given in Table 2. It shows that voltage is increased due to the presence of UPFC \& TCSC.

\section{Conclusion}

TCSC and UPFC are analyzed and the circuit model for thirty bus system is developed using the blocks available in MATLAB. Thirty bus systems with TCSC and UPFC are simulated and the results are presented. The Thyristor Control Series Capacitor has the following advantages such as fast response and smooth reactive power. So the use of UPFC and TCSC helps in increasing the power and voltage. Reactive power increases with the increases in the firing angle of TCSC. Thus variation in the firing angle. The scope of present work is the digital simulation of combined TCSC and UPFC in thirty bus system. This has reduced the reliability and increase the power quality. The simulations are in line predictions Voltages and reactive power increases when the TCSC is applied to the respective buses. The scope of the present work is digital simulation TCSC using MATLAB.

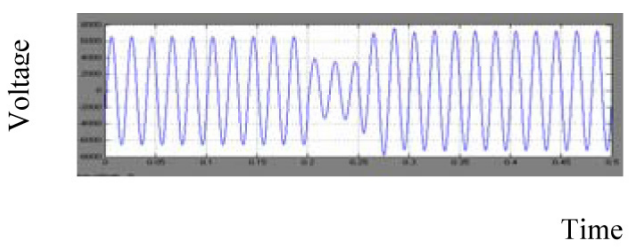

Figure 10. Voltage waveform at bus 21 with UPFC and TCSC.

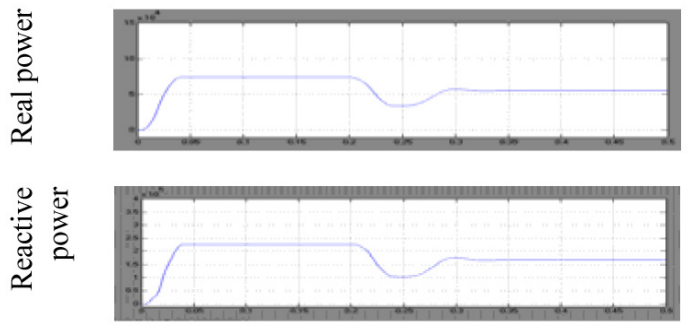

Time

Figure 11. Real and Reactive power waveform at bus 21 with UPFC and TCSC.

Table 1. Summary of real and reactive powers for thirty bus system with and without controllers

\begin{tabular}{lcccc}
\hline $\begin{array}{l}\text { Bus } \\
\text { no }\end{array}$ & $\begin{array}{c}\text { Real power } \\
\text { (MW) } \\
\text { without } \\
\text { controller }\end{array}$ & $\begin{array}{c}\text { Real power } \\
\text { (MW) with } \\
\text { controller }\end{array}$ & $\begin{array}{c}\text { Reactive } \\
\text { power } \\
\text { (MVAR) } \\
\text { without } \\
\text { controller }\end{array}$ & $\begin{array}{c}\text { Reactive } \\
\text { power } \\
\text { (MVAR) } \\
\text { with } \\
\text { controller }\end{array}$ \\
\hline 11 & 0.360 & 0.421 & 0.113 & 0.132 \\
13 & 0.287 & 0.340 & 0.901 & 0.067 \\
19 & 0.267 & 0.346 & 0.105 & 0.136 \\
21 & 0.169 & 0.304 & 0.055 & 0.0991 \\
25 & 0.377 & 0.394 & 1.185 & 1.238 \\
26 & 0.257 & 0.283 & 0.807 & 0.889 \\
\hline
\end{tabular}

Table 2. Summary of voltage for thirty bus system with and without controllers

\begin{tabular}{lcc}
\hline Bus no & $\begin{array}{c}\text { Voltage (KV) without } \\
\text { controller }\end{array}$ & $\begin{array}{c}\text { Voltage (KV) with } \\
\text { controller }\end{array}$ \\
\hline 11 & 6299 & 6798 \\
13 & 5582 & 6075 \\
19 & 6088 & 6876 \\
21 & 4837 & 6497 \\
25 & 6402 & 6554 \\
26 & 5286 & 5548 \\
\hline
\end{tabular}




\section{References}

1. Hingorani G. Facts. IEEE spectrum. 1993, April; 30:40-45.

2. Guyi L. Power electronics in electric static VAR compensators. Proc of IEEE 1994 Mar; 2:45-9.

3. Iravani MR, Dandeno PL, Maratukulam D. Application of static phase shifter in power system. IEEE Trans Power delivers 2001 Sep; 3:210-16.

4. Hingorani NG. FACTS technology and oppurtunities, Flexible AC transmission system- The Key to increased utilization of power systems. IEE colloquim; 12 Jan 1994; London. p4/1-410.

5. Jebaseelan SDSS, Prabu RR. Modelling and simulation of thirty bus system using multiple STATCOM \& TCTC. Eur J Sci Res. 2012 Jul; 81(2):285-97.

6. Iravani MR, Maratukulam D. Review of semi conductor controlled static phase shifters for power system application. IEEE Trans Power System 2007 Jun; 65-9.
7. Gyugi L. Unified power-flow control concept of flexible AC transmission system. IEE Proc C 1995 May; 4:25-7.

8. Jebaseelan SDSS, Prabu RR. Reactive power control using FACTS devices. Indian Stream Research Journal. 2013 Mar; 3(2):45-59.

9. Guyi L. Power electronics in electric utilizes static Var compensators. Proc of IEEE. 1989 Apr; 76:483-84.

10. Fujita H, Akagi $H$, Watanabe Y. Dynamic control and Performance of a United Power electronics. IEEE Transactions on Power Electronics.

11. Jebaseelan SDSS, Prabu RR. Performance of Thirty Bus System with and without STATCOM. International Conference on Trends in Electrical, Electronics and Power Engineering, (ICTEEP). 2012 Jul 15-16; Singapore. p. 87-91.

12. Jebaseelan SDSS, Prabu RR. Power Quality Improvement of Eight Bus System using TCTC. INTERACT-2010. 2010 Dec 3-5; Sathyabama University. p. 186-88. 